\title{
Oxidative status of cardinal ligament in pelvic organ prolapse
}

\author{
GUI FANG ${ }^{1}$, LI HONG ${ }^{2}$, CHENG LIU $^{2}$, QING YANG ${ }^{2}$, QIFAN ZHANG $^{2}$, YANG $^{2}{ }^{2}$, \\ BINGSHU LI ${ }^{2}$, DEBIN WU ${ }^{2}$, WENYING WU ${ }^{1}$ and HUA SHI ${ }^{1}$ \\ Departments of ${ }^{1}$ Obstetrics and Gynecology Ultrasound, and ${ }^{2}$ Obstetrics and Gynecology, \\ Renmin Hospital of Wuhan University, Wuhan, Hubei 430060, P.R. China
}

Received January 6, 2017; Accepted September 22, 2017

DOI: $10.3892 /$ etm.2018.6633

\begin{abstract}
Pelvic organ prolapse (POP) is a common and distressing health problem in adult women, but the pathophysiological mechanism is yet to be fully elucidated. Previous studies have indicated that oxidative stress may be associated with POP. Thus, the aim of the present study was to investigate the oxidative status of pelvic supportive tissue in POP and further demonstrate that oxidative stress is associated with the pathogenesis of POP. A total of 60 samples were collected from females undergoing hysterectomy for POP or cervical intraepithelial neoplasia (CIN). This included 16 females with POP II, 24 females with POP III-IV (according to the POP-Q system) and 20 females with CIN II-III as the control group. Immunohistochemistry was utilized to measure the expression of oxidative biomarkers, 8 -hydroxydeoxyguanosine (8-OHdG) and 4-hydroxynonenal (4-HNE). Major antioxidative enzymes, mitochondrial superoxide dismutase (MnSOD) and glutathione peroxidase 1 (GPx1) were measured through reverse transcription-quantitative polymerase chain reaction, western blotting and enzyme activity assays. The results demonstrated that in the cardinal ligament, the expression of $8-\mathrm{OHdG}$ and 4-HNE was higher in the POP III-IV group compared with the POP II group and control group. The MnSOD and GPx1 protein level and enzyme activity were lower in the POP III-IV group compared with the POP II or the control group, while the mRNA expression level of MnSOD and GPx1 was increased. In conclusion, oxidative damage is increased in the pelvic supportive ligament of female patients with POP and the antioxidative defense capacity is decreased. These results support previous findings that oxidative stress is involved in the pathogenesis of POP.
\end{abstract}

Correspondence to: Professor Li Hong, Department of Obstetrics and Gynecology, Renmin Hospital of Wuhan University, 99 Zhangzhidong Road, Wuhan, Hubei 430060, P.R. China E-mail: drhongli7777@gmail.com

Key words: oxidative stress, pelvic organ prolapse, 8-hydroxydeoxyguanosine, 4-hydroxynonenal, mitochondrial superoxide dismutase, glutathione peroxidase 1

\section{Introduction}

Pelvic organ prolapse (POP), presenting symptoms including uterine prolapse, bladder prolapseand rectal prolapse, is a common and distressing health problem in adult women, which can affect $\sim 50 \%$ of women over the age of 50 (1). In the USA, the total number of women who undergo surgery for POP is projected to increase from 166,000 (in 2010) to 245,970 in 2050 (2) and the incidence would peak in women aged between 60 to 79 years $(3,4)$. The annual cost for POP surgery was $\$ 1.4$ billion between 1996 and 2005 (5). The precise pathogenesis of POP is still unknown, but it is believed to be multifactorial. Environmental factors, including age, hormonal status, constipation, smoking, obesity, prior surgery, increased infant birth weight, episiotomy, vaginal parity and extended second stage of labor, have been identified as key risk factors in the development of POP (6). Other factors, including chronic illnesses that increase intra-abdominal pressure, underlying neurological disease and a decrease of estrogen receptor in the pelvic supportive tissue, are also considered to be risk factors $(7,8)$. However, environmental factors alone cannot explain the development and progression of POP. For example, severe female pelvic floor dysfunction has been reported in nulliparous women with minimal risk factors, while a large number of multiparous women do not develop POP (9-11).

Oxidative stress is caused by an imbalance of reactive oxygen species (ROS) and antioxidant defense systems in a cell, tissue or organ (12). ROS, including the superoxide radical anion $\left(\mathrm{O}_{2}^{-}\right)$, hydroxyl radical and hydrogen peroxide $\left(\mathrm{H}_{2} \mathrm{O}_{2}\right)$, are produced as byproducts of normal cellular metabolism (13). They are reactive molecules due to their unpaired electrons and can react spontaneously with biomolecules such as DNA, RNA, protein and lipids, leading to cell death and disease $(14,15)$. Oxidative stress damage occurs when levels of ROS exceed the cell's antioxidant defense capacity (16). As previously reported, isoprostanes, reliable biomarkers of oxidative stress, are higher in women with uterine prolapse compared with non-prolapse women, in the cardinal ligament and urine samples (17). Selenium is a key component of glutathione peroxidase (GPx), which can indirectly reflect antioxidant capacity (18). It was previously demonstrated that serum selenium concentration is significantly lower in pelvic organ prolapse-affected buffaloes compared with control group buffaloes (19). Recently, a genetic predisposition investigation revealed that oxidative-related genes are associated 
with POP (20). In addition, Visco and Yuan (21) demonstrated that the gene expression of DSCR-1, an antioxidative related gene, and its gene product calcipressin 1 , which can protect cells from oxidative stress, was underexpressed in pubococcygeus muscle from women with prolapse. This indicated that the pelvic floor may suffer from oxidative stress, leading to the damage of pelvic floor tissues. In addition, oxidative stress has been demonstrated to regulate matrix metalloproteinase (MMPs) and tissue inhibitors of metalloproteinases (TIMPs), thus leading to decreased collagen and elastin synthesis in fibroblasts and smooth muscle cells (22-25). It has also been documented that abnormal collagen metabolism is involved in the molecular pathology of POP (26-30). Therefore, in the present study, it was hypothesized that oxidative stress may be involved in the pathogenesis of POP.

Several specific oxidative stress markers are required to assess redox status. 8-hydroxydeoxyguanosine (8-OHdG) is the most studied product of oxidative DNA damage, produced via hydroxylation at the C-8 position of the guanine base on DNA by extremely active hydroxyl radicals (31). 4-hydroxynonenal (4-HNE), a product of cell membrane lipid peroxidation, can be generated by oxidative stimuli and has been detected in numerous diseases, including diabetes and Parkinson's disease (32-33). The formation of 8-OHdG, 4-HNE and 4-HNE-protein conjugation have become common oxidative biomarkers used to estimate ROS-induced DNA and lipid damage in vivo with high precision (34-37).

In the endogenous defense system against ROS damage in humans, GPx and superoxide dismutase (SOD) are the two critical antioxidant enzymes (38). There are three well-known forms of SOD, namely cytosolic copper/zinc SOD (CuZnSOD, SOD1), mitochondrial SOD (MnSOD, SOD2) as well as extracellular CuZnSOD (SOD3). MnSOD is located in the mitochondria, a major site of ROS production, which indicates that MnSOD may serve a key function in the antioxidant defense system (38). MnSOD is the only mitochondrial matrix enzyme that transforms $\mathrm{O}_{2}^{-}$, generated from complexes I and III of the electron transport chain, into $\mathrm{H}_{2} \mathrm{O}_{2}$, which then diffuses out of the mitochondrial matrix and is subsequently neutralized to $\mathrm{H}_{2} \mathrm{O}$ and $\mathrm{O}_{2}$ by GPx1 (39). Of the four GPx isoenzymes, GPx1 is the most abundant. It is a selenium-dependent enzyme that protects cells against oxidative damage through scavenging $\mathrm{H}_{2} \mathrm{O}_{2}$ and other organic peroxides with reduced glutathione (40). Thus, MnSOD and GPx1 serve the most important role in maintaining equilibrium between oxidative and antioxidative activity under normal physiological conditions (38-40).

The uterosacral and cardinal ligaments are important parts of the pelvic floor support system to the cervix and the upper vagina (41). Thus, in the present study, the oxidative stress biomarkers, 8-OHdG and 4-HNE, and the major antioxidative enzymes, MnSOD and GPx1, were evaluated in the cardinal ligaments. The aim of the present study was to investigate the oxidative status of pelvic supportive tissue in POP and further demonstrate that oxidative stress is involved in the pathogenesis of POP.

\section{Patients and methods}

Patients. The present study was conducted in the Department of Obstetrics and Gynecology, Renmin Hospital of Wuhan
University (Wuhan, China), and approved by the Institutional Ethic Committee of the hospital. Informed consent was obtained from all patients. From January 2012 to December 2013, cardinal ligament tissue was obtained from 60 female patients (age range, 42-69 years old) undergoing hysterectomy at Renmin Hospital of Wuhan University. The patients were divided into three groups: 20 patients range from 47 to 69 year old who were undergoing hysterectomy for cervical intraepithelial neoplasia (CIN) II or CIN III (42) were included as the control group; 16 women (age range, 42-63 years old) who were diagnosed with POP II according to the POP-Q system (43) were included in the POP II group; and 24 women range from 48-66 years old who were diagnosed with POP III or POP IV were included in the POP III-IV group.

Patients with malignancy, hormone-related diseases (including leiomyoma, endometriosis and adenomyosis), diabetes, asthma or cardiovascular disease were excluded since these disorders are known to be associated with oxidative stress (44-47).

Immunohistochemistry. All tissue samples were fixed in $4 \%$ paraformaldehyde at $37^{\circ} \mathrm{C}$ for $8 \mathrm{~h}$, then embedded in paraffin. Samples were cut into $4-\mu \mathrm{m}$ thick sections and heated at $62^{\circ} \mathrm{C}$ for $2 \mathrm{~h}$. Each sample was passed through xylene and ethanol series to remove paraffin. Then, samples were incubated with $1 \% \mathrm{H}_{2} \mathrm{O}_{2}$ to prevent endogenous peroxidase activities. Sections were boiled in sodium citrate antigen retrieval buffer $\left(10 \mathrm{mmol} / \mathrm{l} ; \mathrm{pH}<6.0 ; 95^{\circ} \mathrm{C}\right)$ for $20 \mathrm{~min}$ and then cooled down to room temperature. Then, specimens were washed with PBS and placed in the immunohistochemistry container. Immunohistochemistry was performed using antibodies against 8-OHdG (mouse monoclonal antibody; 1:100; Abcam, Cambridge,UK; cat. no. ab62623) and 4-HNE (rabbit polyclonal antibody; 1:100; Abcam; cat. no. ab46545), following the manufacturer's protocols. Secondary antibodies were goat anti-mouse polyclonal horseradish peroxidase (HRP)-conjugated Immunoglobulin G (IgG; 1:1,000; cat. no. ab97023) and goat anti-rabbit polyclonal HRP-conjugated $\operatorname{IgG}(1: 1,000$; cat. no. ab97051; both Abcam). The staining procedure was performed using DAB (DAB-0031; Fuzhou Maixin Biotech Co., Ltd., Fuzhou, China) according to the DAB detection kit protocol. All immunohistochemical images were obtained using a BH-2 light microscope (Olympus Corporation, Tokyo, Japan) and analyzed using Image J2x 2.1.4.7 software (National Institutes of Health, Bethesda, MD, USA).

Reverse transcription-quantitative polymerase chain reaction $(R T-q P C R)$. Total RNA was extracted from freshly collected cardinal ligament tissue with TRIzol reagent (Invitrogen; Thermo Fisher Scientific, Inc., Waltham, MA, USA), following the manufacturer's protocol. The obtained RNA concentration and purity were detected by OD260/280 nm absorption ratio. The extracted RNA was stored at $-80^{\circ} \mathrm{C}$ until cDNA synthesis. cDNA synthesis was performed using a RevertAid First Strand cDNA Synthesis kit (Thermo Fisher Scientific, Inc.), according to the manufacturer's protocol. The synthesized cDNA was stored at $-20^{\circ} \mathrm{C}$ prior to $\mathrm{qPCR}$. Specific primer pairs were designed as follows: MnSOD forward, 5'-GACATATGAAGC ACAGCCTCCCCGACC-3' and reverse, 5'-GCAAGCTTG CATAACGATCGTGGTTTAC-3'; GPx1 forward, 5'-CGCTTC 

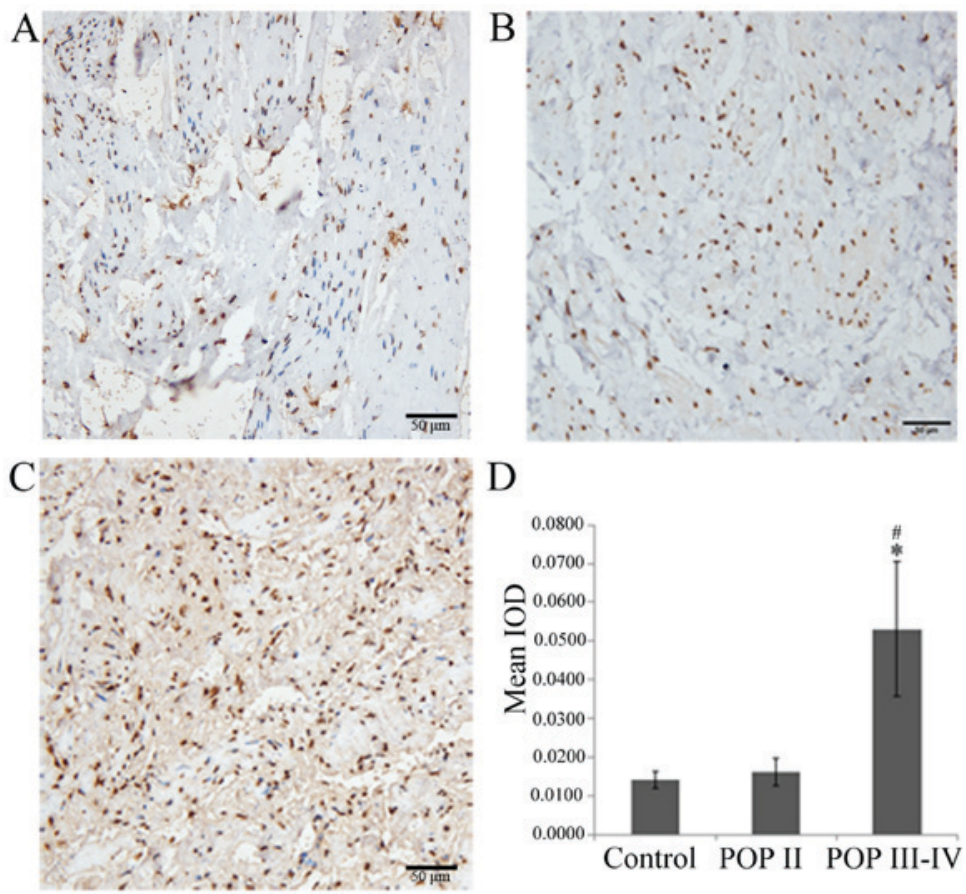

$\mathrm{D}$

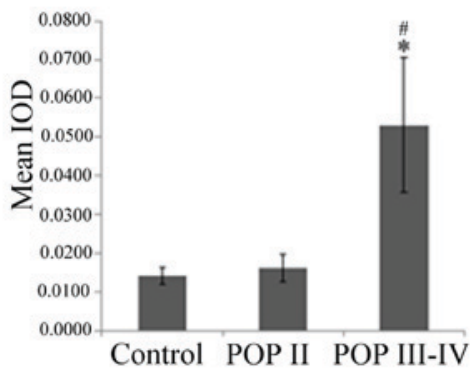

Immunohistochemistry analysis for $8-\mathrm{OHdG}$

Figure 1. Immunohistochemistry analysis of 8-OHdG expression. (A) Control group, (B) POP II group, (C) POP III-IV group, (D) quantification of staining in each group. Data are expressed as the mean \pm standard deviation. Scale bar, $50 \mu \mathrm{m}$. ${ }^{*} \mathrm{P}<0.05$ vs. control group. ${ }^{*} \mathrm{P}<0.05$ vs. POP II group. 8 -OHdG, 8-hydroxydeoxyguanosine; POP, pelvic organ prolapse; IOD, integrated optical density.

CAGAGCATTGACATC-3' and reverse, 5'-CGAGGTGGTATT TTCTGTAAGATCA-3'. $\beta$-actin (forward, 5'-GTTGCTATCC AGGCTGTG-3' and reverse, 5'-TGATCTTGATCTTCATTG TG-3') served as the internal control. qPCR was performed in triplicate using the standard PCR kit of SYBR-Green Premix Ex Taq (Clontech Laboratories, Inc., Mountainview, CA, USA) and the ABI Prism 7500 system (Applied Biosystems; Thermo Fisher Scientific, Inc.). The thermocycling conditions were as follows: $30 \mathrm{sec}$ at $95^{\circ} \mathrm{C}$, followed by 40 cycles for $5 \mathrm{sec}$ at $95^{\circ} \mathrm{C}$ and $34 \mathrm{sec}$ at $60^{\circ} \mathrm{C}, 15 \mathrm{sec}$ at $95^{\circ} \mathrm{C}, 1 \mathrm{~min}$ at $60^{\circ} \mathrm{C}, 15 \mathrm{sec}$ at $95^{\circ} \mathrm{C}$ and $15 \mathrm{sec}$ at $60^{\circ} \mathrm{C}$. Relative gene expression was analyzed using the $2^{-\Delta \Delta \mathrm{Cq}}$ method (48) with a correction for different amplification efficiencies.

Western blot analysis. Western blot analysis was performed according to standard procedures. Total protein was extracted from cardinal ligament tissue and quantified using an enhanced BCA protein assay kit (cat. no. P0010; Beyotime Institute of Biotechnology, Haimen, China). Equal amounts of protein samples $(20 \mu \mathrm{g})$ from each sample were separated in a $10 \%$ SDS-polyacrylamide gel with 5\% stacking gel in SDS-Tris-glycine running buffer. Then the proteins were transferred to a polyvinylidene difluoride membrane by standard procedures. The membranes were blocked with $5 \%$ nonfat dry milk in TBS for $1 \mathrm{~h}$ at room temperature and incubated overnight with primary antibodies at $4^{\circ} \mathrm{C}$ : MnSOD (rabbit polyclonal antibody, cat. no. 06-984, 1:1,000; EMD Millipore, Billerica, MA, USA) and GPx1 (rabbit polyclonal antibody; cat. no. ab22604; 1:1,000; Abcam). Antibodies against GAPDH were also utilized (rabbit polyclonal antibody; cat. no. ab9485; 1:1,000; Abcam). After washing with TBS-Tween-20 (TBST) three times, membranes were incubated with secondary fluorescence antibodies (IRDye 800CWgoat anti-rabbit secondary antibodies; cat. no. 926-32211; 1:10,000; LI-COR Biosciences, Lincoln, NE, USA) for $1 \mathrm{~h}$ at room temperature. After rewashing with TBST three times at room temperature, the immunoreactive bands were detected and analyzed using the odyssey 3.0 image system software (LI-COR Biosciences).

Measurement of total antioxidant capacity $(T-A O C)$ and enzyme activity of SOD and GPx. The T-AOC assay kit (Nanjing jiancheng Bioengineering Institute, Nanjing, China; cat. no. A015) and SOD enzyme activity assay kit (Nanjing Jiancheng Bioengineering Institute; cat. no. A001-3) and GPx enzyme activity assay kit (Nanjing jiancheng Bioengineering Institute; cat. no. A005) were purchased from Nanjing Jiancheng Bioengineering Institute, Nanjing, China. The assays were performed according to the manufacturer's protocol.

Statistical analysis. Data are presented as the mean \pm standard deviation. SPSS 13.0 statistical analysis software (SPSS, Inc., Chicago, IL, USA) was used to analyze the results. One-way analysis of variance was performed to compare the means among groups and the post-hoc LSD test was used to make multiple comparisons. $\mathrm{P}<0.05$ was considered to indicate a statistically significant difference.

\section{Results}

8-OHdG and 4-HNE are overexpressed in patients with POP $I I I-I V$. Immunohistochemistry results indicated that $8-\mathrm{OHdG}$ was expressed in the nuclei and 4-HNE was expressed in the cytoplasm of cardinal ligaments, respectively (Figs. 1 and 2). 

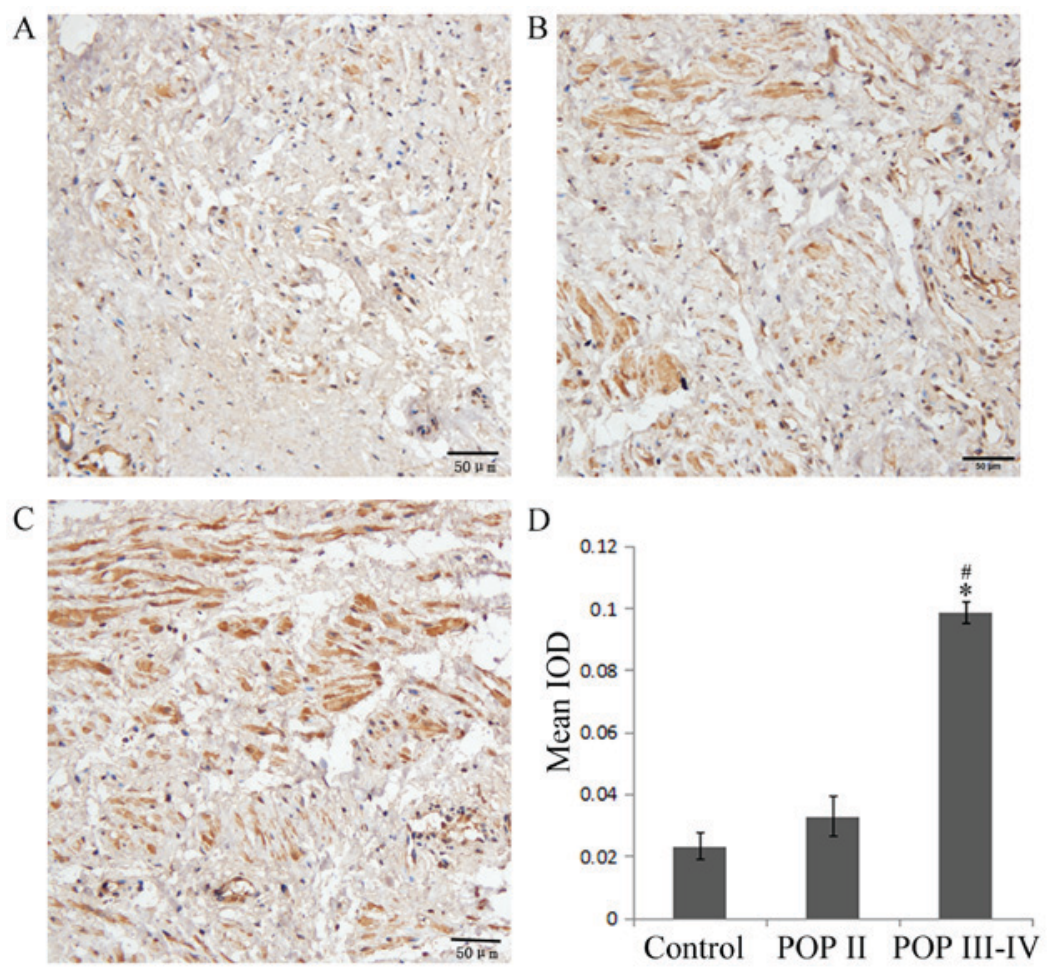

Immunohistochemistry analysis for 4-HNE

Figure 2. Immunohistochemistry analysis of 4-HNE expression. (A) Control group, (B) POP II group, (C) POP III-IV group, (D) quantification of staining in each group. Data are expressed as the mean \pm standard deviation. Scale bar, $50 \mu \mathrm{m}$. "P<0.05 vs. control group. ${ }^{*} \mathrm{P}<0.05$ vs. POP II group. 4-HNE, 4-hydroxynonenal; POP, pelvic organ prolapse; IOD, integrated optical density.
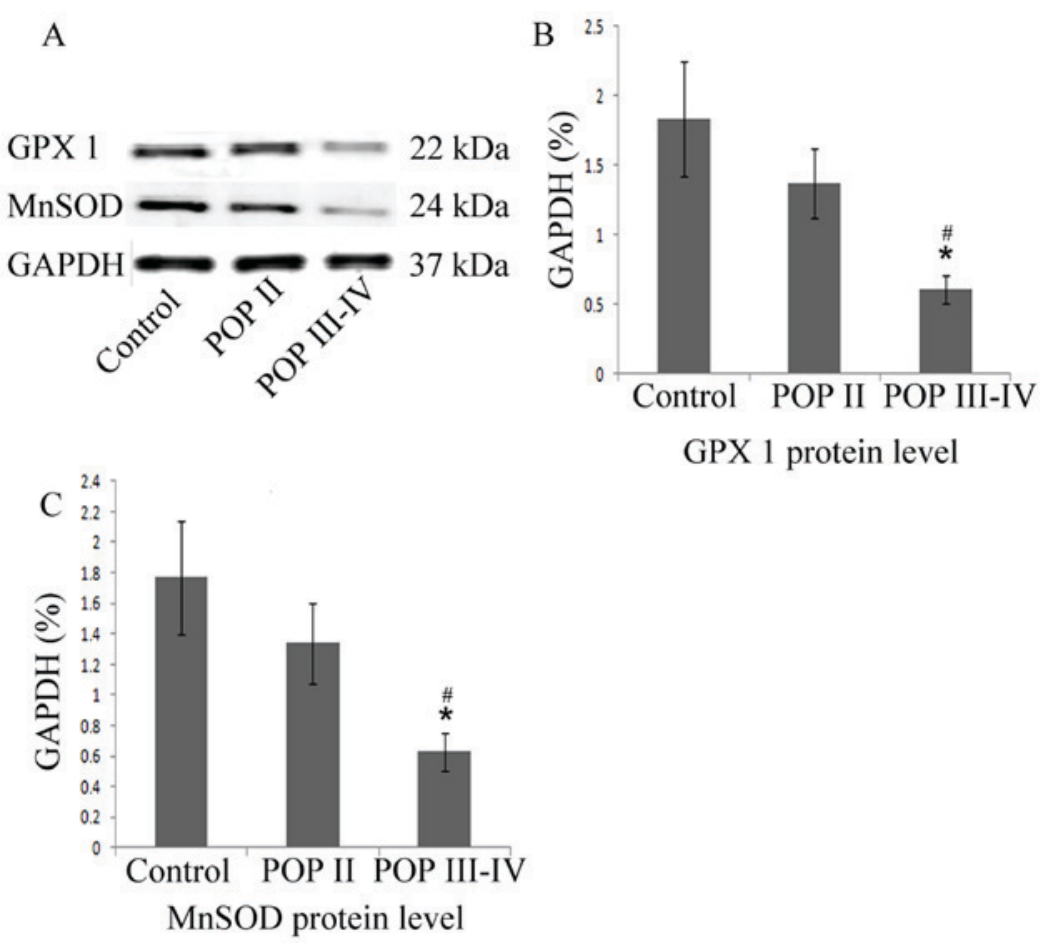

Figure 3. Western blot analysis of MnSOD and GPx1 protein expression. Data are expressed as the mean \pm standard deviation. (A) Western blot analysis. (B) Quantification of GPx1 expression relative to GAPDH. (C) Quantification of MnSOD relative to GAPDH. ${ }^{*} \mathrm{P}<0.05$ vs. control group. ${ }^{\text {P }}<0.05$ vs. POP II group. POP, pelvic organ prolapse; MnSOD, mitochondrial superoxide dismutase; GPx1, glutathione peroxidase 1.

The expression of 8-OHdG and 4-HNE was significantly higher in the POP III-IV group compared with the POP II group $(\mathrm{P}<0.05$; Figs. 1D and 2D) and the control group
$(\mathrm{P}<0.05$; Figs. 1D and 2D). No significant differences were observed between the POP II group and the control group. These results indicated that the oxidative markers $8-\mathrm{OHdG}$ 
A
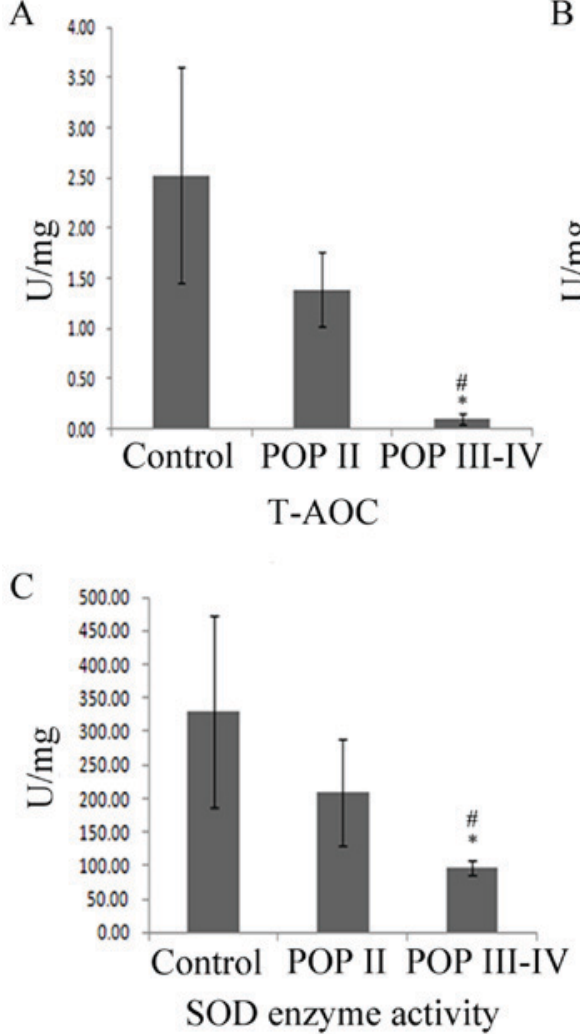

B

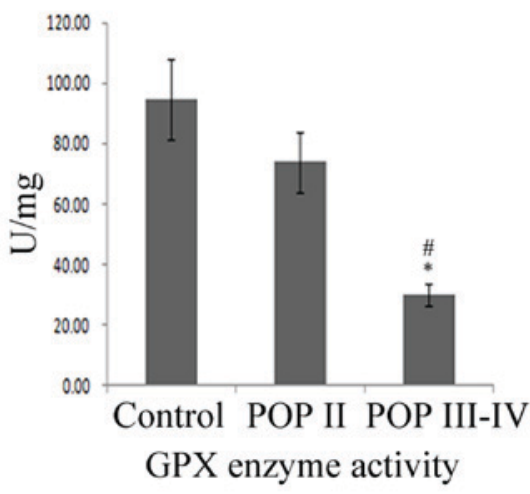

Figure 4. Enzyme activity analysis for (A) T-AOC, (B) SOD and (C) GPx. Data are expressed as the mean \pm standard deviation. *P $<0.05$ vs. control group. ${ }^{\#} \mathrm{P}<0.05$ vs. POP II group. T-AOC, total antioxidant capacity; SOD, superoxide dismutase; GPx, glutathione peroxidase; POP, pelvic organ prolapse.

and 4-HNE are expressed at higher levels in patients with severe POP compared with patients with mild POP or healthy controls.

MnSOD and GPxl protein level is decreased in patients with $P O P I I I-I V$. As indicated in the western blot analysis (Fig. 3), the MnSOD and GPx1 protein levels were significantly lower in the POP III-IV group compared with the POP II group and the control group $(\mathrm{P}<0.05)$. No significant differences were observed between the control group and the POP II group. These results indicated that the antioxidative proteins MnSOD and GPx1 are expressed at lower levels in patients with severe POP compared with patients with mild POP or healthy controls.

T-AOC, SOD and GPx enzyme activity is decreased in patients with POP III-IV. In order to detect the primary defense capacity to oxidative stress, T-AOC, SOD and GPx enzyme activity was detected among the three groups. As shown in Fig. 4, the T-AOC, SOD and GPx enzyme activity was significantly lower in the POP III-IV group compared with the POP II group and the control group $(\mathrm{P}<0.05)$. No significant differences were observed between the control group and the POP II group $(\mathrm{P}>0.05)$. These results indicated that T-AOC, SOD and GPx enzyme activity was lower in patients with severe POP compared with patients with mild POP or healthy controls.

MnSOD and GPXI mRNA level is increased in POP group. The aforementioned results suggested that MnSOD and GPx1 protein level and enzyme activity were lower in the POP III-IV group compared with the control group. Thus, the mRNA level was also compared among groups by RT-qPCR (Fig. 5). The results indicated that MnSOD and GPx1 mRNA expression was significantly higher in the POP III-IV group compared with the POP II group and the control group $(\mathrm{P}<0.05)$. No significant differences were observed between the control group and the POP II group.

\section{Discussion}

POP is primarily characterized by biomechanical defects of pelvic supportive tissues and increased apoptotic cell death and altered extracellular matrix (ECM) metabolism may be involved $(49,50)$. It has been documented that oxidative stress is a common mediator of apoptosis in numerous cell types and it has been observed in the pelvic supportive tissues of women with POP (51).

Oxidative stress results from an imbalance of ROS and antioxidant defense systems in a cell, tissue or organ and has been identified to be involved in multiple diseases (52-56). Pregnancy, childbirth, age, obesity, constipation and smoking are well-established risk factors for POP, and these risk factors have been demonstrated to be associated with oxidative stress (6-8). Therefore, it was speculated that oxidative stress may be involved in the pathogenesis of POP.

Previous studies have reported that oxidative stress may be involved in the pathogenesis of POP and certain antioxidative-related genes, including Adapt 78 and DSCR-1 have been identified to be associated with POP $(17,20,21)$. 
A

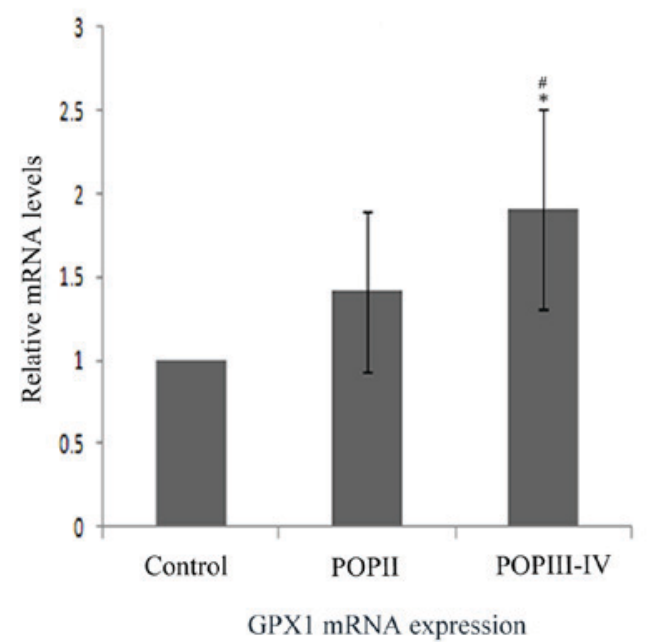

B

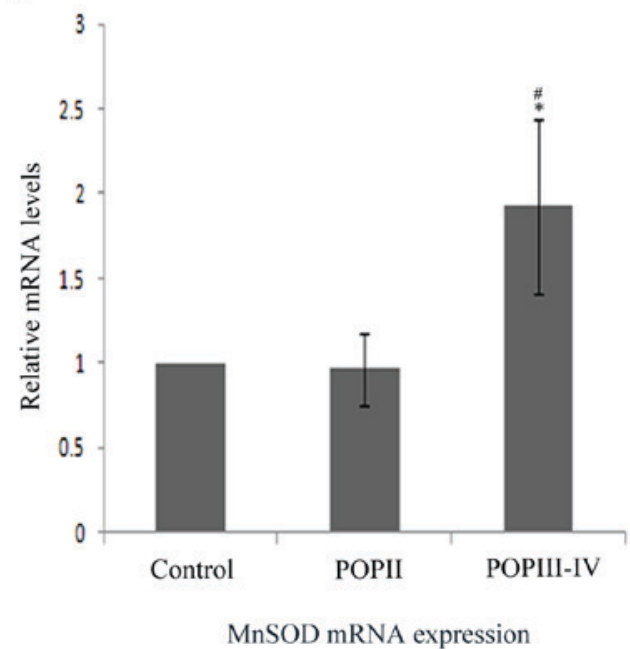

Figure 5. Reverse transcription-quantitative polymerase chain reaction analysis of (A) MnSOD and (B) GPx1 mRNA expression. Data are expressed as the mean \pm standard deviation. ${ }^{*} \mathrm{P}<0.05$ vs. control group. ${ }^{*} \mathrm{P}<0.05$ vs. POP II group. POP, pelvic organ prolapse; MnSOD, mitochondrial superoxide dismutase; GPx1, glutathione peroxidase 1 .

However, none of these studies detected the oxidative/ antioxidative status in the pelvic supportive ligament of patients with POP. The purpose of the current study was to investigate the oxidative damage and antioxidative status of the pelvic supportive ligament in patients with POP, and further demonstrate that oxidative stress may be involved in the pathogenesis of POP.

In the present study, it was demonstrated that oxidative damage markers, 8-OHdG and 4-HNE, were increased in the pelvic supportive ligament of patients with severe POP compared with controls, while the protein levels of the major antioxidative enzymes, MnSOD and GPx1, were decreased. T-AOC, SOD and GPx enzyme activity were also decreased in patients with severe POP. From these observations, it may be concluded that in patients with severe POP, oxidative damage is increased, while the antioxidative defense system is weakened. These results supported previous findings that oxidative stress is associated with the pathogenesis of POP.

Oxidative stress reflects an excessive bioavailability of ROS, which is the result of an imbalance between production and destruction of ROS. ROS such as $\mathrm{O}_{2}^{-}$and $\mathrm{H}_{2} \mathrm{O}_{2}$ have been demonstrated to serve important roles as signal transduction intermediates (57-66). For instance, ROS have been demonstrated to activate downstream signaling molecules, induce the expression of redox-sensitive genes and regulate cell proliferation and migration, which has been demonstrated to be associated with POP (57-62). ROS can also induce mitochondrial damage and dysfunction, resulting in impairment of the Krebs cycle and activation of apoptotic pathways (58,63-66), while oxidative stress-induced apoptotic cell death is reported to be involved in the pathological generation of oxidative stress-related diseases $(67,68)$. Previous studies have focused on ROS, the synthesis and decomposition process of ECM. ROS have been demonstrated to regulate MMPs through changes in expression and by direct interactions with Zn-thiol groups (69), activating MMP secretion (25) or through nitration of cysteine residues in the autoinhibitory domain (70) and suppressed collagen production in fibroblasts (71). An association between the expression of MMP-2 and TIMP-2 in the uterosacral ligament and the occurrence of uterine prolapse has also been demonstrated (72). Conversely, reactive nitrogen species, such as $\mathrm{ONOO}^{-}$, can induce nitration of TIMP-4 and then attenuate its inhibitory activity against MMP-2 activity in cells (73). Therefore, oxidative stress may be involved in the pathogenesis of POP through multiple mechanisms, including cell apoptosis and the synthesis and decomposition process of ECM, which are associated with POP.

8-OHdG and 4-HNE are oxidative damage markers of DNA and lipids, respectively (34-37). However, 8-OHdG and 4-HNE may also serve other functions. For example, 8-OHdG has gained much attention due to its mutagenic potential to pair with adenine, instead of cytosine, resulting in $\mathrm{G}: \mathrm{C}$ to $\mathrm{T}: \mathrm{A}$ transversions if the damage is not repaired before DNA replication $(34,74)$. This may constitute $20-30 \%$ of the deoxyguanosine damage in DNA, equivalent to $5-11 \%$ of the total DNA nucleoside damage and has been demonstrated to be associated with many oxidative-related diseases or processes, including cancer, aging and neurodegeneration (75,76). 4-HNE, which was initially considered as merely a toxic end-product of lipid peroxidation (LPO) derived from oxidized $\omega-6$ polyunsaturated fatty acids such as arachidonic acid, has been demonstrated to be an important second messenger signaling molecule; alterations in the intracellular levels of 4-HNE are associated with signaling for proliferation, transformation, apoptosis and differentiation in numerous cell types (77-81). Chaudhary et al (82) demonstrated that 4-HNE can cause toxicity to cells through apoptosis and necrosis in a dose-dependent manner. Furthermore, through interactions with cell membrane receptors as well as transcription repressors, 4-HNE could have extensive effects on the expression of genes regulating multiple cellular processes, including oxidative stress (82). Therefore, 4-HNE may be a key mediator of oxidative stress-induced apoptosis. As a result, aside from being markers of oxidative damage to DNA and lipids, 8-OHdG and 4-HNE can also cause cell and tissue injury multiple mechanisms, which may lead to disease, including 
POP. This may partly explain the increased levels of 8-OHdG and 4-HNE in the pelvic supportive ligament of patients with POP III-IV in the present study.

Antioxidant defense system enzymes, including GPx and SOD, reduce oxidative stress through inactivation of ROS. GPx1 detoxifies $\mathrm{H}_{2} \mathrm{O}_{2}$ and lipid peroxides using reduced glutathione to protect cells against oxidative and nitrosative stress (83). GPx1 knockdown mice (GPX1 $1^{--}$) exhibit increased mitochondrial ROS production and oxidative mitochondrial DNA damage (84). MnSOD is an important first defense against mitochondrial oxidative stress and damage to mitochondrial integrity (85). Homozygous MnSOD knockout (Sod2 ${ }^{-/}$) mice were reported to be neonatal lethal, produce low levels of cellular ATP, exhibit low $\mathrm{O}_{2}$ consumption and generate increased levels of superoxide (86). Meanwhile, enhancement of MnSOD protein levels in Sod 2 transgenic mice notably reduced markers of oxidative stress and protected against age-related increases of proapoptotic signaling, including Bax and cleaved caspase-3. It also reduced the number of apoptotic nuclei and the amount of DNA fragmentation in mouse hearts (87). Additionally, MnSOD could serve a key function in protecting RNA and DNA, thus maintaining normal protein expression, through interacting with RNA or DNA, or interacting with proteins involved in DNA repair, apoptosis, translation and metabolic function $(88,89)$. The overexpression of MnSOD appears to increase mitochondrial antioxidative capacity and reduce apoptosis, which has been demonstrated in the liver, brain and skeletal muscle (90-93).

Previous research into the pathogenesis of POP has demonstrated that alterations in ECM metabolism and cell apoptosis are involved $(27-30,49)$. It has been proposed that alterations in the smooth muscle content and function may contribute to the development of POP (94-97). Takacs et al (50) demonstrated that the smooth muscle component of the cervical uterosacral ligaments (USL) is decreased significantly and the apoptosis rate is increased in women with uterine prolapse. Decreased smooth muscle content of the USL due to increased apoptosis may also serve a key function in the pathogenesis of POP. On the basis of previous research, it is obvious that oxidative stress, oxidative damage molecules such as 4-HNE and antioxidative enzymes such as MnSOD can regulate or influence cell apoptosis or MMPs and TIMPs, which are associated with ECM metabolism. Decreased protein level and activity of antioxidants GPx1 and MnSOD, as in the present study, is likely to lead to DNA, lipid, protein and mitochondrial function damage and disrupted electron transport, which in turn would lead to increased ROS production. This could form a feedback loop and finally lead to the development of POP.

The observations in the current study support the proposal that oxidative stress is involved in the pathogenesis of POP. This may be through regulating or influencing cell apoptosis and ECM protein metabolism, thus influencing the content and function of the pelvic supportive tissue in POP women. Furthermore, with the decrease of antioxidative capacity, oxidative stress increases, which further leads to increased oxidative damage in the antioxidative defense system, forming a negative feedback loop. Therefore, different degrees of antioxidative capacity could lead to different extents of oxidative stress and thus contribute to different severities of POP. This would mean that the most damaged antioxidative defense capacity in the severe POP group would lead to the greatest oxidative injures in cell and tissue, probably through damage to mitochondria, ECM metabolism and induced cell apoptosis. Therefore, this would result in a greater extent of damage to the pelvic supportive tissue compared with mild POP or healthy controls.

Notably, in the present study, protein expression and enzyme activity of MnSOD and GPx1 were decreased, while the mRNA expression level of the two enzymes increased in patients with POP compared with the control group. As discussed above, ROS can activate downstream signaling targets and induce the expression of redox-sensitive genes. Thus, ROS accumulates in cells and tissue, and activates the expression of protective proteins when oxidative stress occurs, including MnSOD and GPx1. The mRNA expression of these proteins also increases. The specific mechanism for the decrease of MnSOD and GPx1 protein expression and enzyme activity in women with POP remains unknown. Further studies are therefore required to elucidate this.

As previously reported, selenium-enriched food and exercise training is effective in upregulating GPx and MnSOD activity, as well as reducing apoptosis in a range of tissues (98-101). The antioxidant enzyme is a potential candidate for the treatment of ROS-related disease, suggesting that selenium-enriched food and exercise training may reduce or delay the occurrence of POP.

In conclusion, the present study demonstrated that oxidative damage is increased in women with severe POP, while the antioxidative defense capacity is decreased. Oxidative stress may be involved in the pathogenesis of POP via regulation of cell apoptosis and ECM metabolism, but the underlying mechanisms require further investigation. The methods that eliminateoxidative damage or enhance antioxidant capacity may therefore be beneficial to delaying the progress of or for the treatment of POP.

\section{Acknowledgements}

Not applicable.

\section{Funding}

The present study was supported by the National Natural Science Foundation of China (grant no. 81270684) and the Foundation of Collaborative and Innovation Projects of Wuhan University School of Medicine (grant no. 523-266078).

\section{Availability of data and materials}

The analyzed data sets generated during the present study are available from the corresponding author on reasonable request.

\section{Authors' contributions}

GF conceived and designed the experiments and wrote the manuscript. LH participated in designing the experiments, revised it critically for important intellectual content and gave their final approval of the version to be published. CL, QY, QZ, YL helped with the western blot and PCR experiments. BL, DW, WW and HS helped with tissue collection. All authors read and approved the final manuscript. 


\section{Ethics approval and consent to participate}

The present study was conducted in the Department of Obstetrics and Gynecology, Renmin Hospital of Wuhan University and approved by the Institutional Ethic Committee of the hospital. Informed consent was obtained from all patients.

\section{Patient consent for publication}

Not applicable.

\section{Competing interests}

The authors declare that they have no competing interests.

\section{References}

1. Samuelsson EC, Victor FT, Tibblin G and Svärdsudd KF Signs of genital prolapse in a Swedish population of women 20 to 59 years of age and possible related factors. Am J Obstet Gynecol 180: 299-305, 1999.

2. Wu JM, Kawasaki A, Hundley AF, Dieter AA, Myers ER and Sung VW: Predicting the number of women who will undergo incontinence and prolapse surgery, 2010 to 2050. Am J Obstet Gynecol 205: 230.e1-e5, 2011.

3. Boyles SH, Weber AM and Meyn L: Procedures for pelvic organ prolapse in the United States, 1979-1997. Am J Obstet Gynecol 188: 108-115, 2003

4. Shah AD, Kohli N, Rajan SS and Hoyte L: The age distribution, rates, and types of surgery for pelvic organ prolapse in the USA. Int Urogynecol J Pelvic Floor Dysfunct 19: 421-428, 2008.

5. Brown JS, Waetjen LE, Subak LL, Thom DH, Van den Eeden S and Vittinghoff E: Pelvic organ prolapse surgery in the United States, 1997. Am J Obstet Gynecol 186: 712-716, 2002.

6. Nikolova G, Lee H, Berkovitz S, Nelson S, Sinsheimer J, Vilain E and Rodríguez LV: Sequence variant in the laminin gammal (LAMC1) gene associated with familial pelvic organ prolapse. Hum Genet 120: 847-856, 2007.

7. Olsen AL, Smith VJ, Bergstrom JO, Colling JC and Clark AL: Epidemiology of surgically managed pelvic organ prolapse and urinary incontinence. Obstet Gynecol 89: 501-506, 1997.

8. Zhu L, Lang J, Feng R, Chen J and Wong F: Estrogen receptor in pelvic floor tissues in patients with stress urinary incontinence. Int Urogynecol J Pelvic Floor Dysfunct 15: 340-343, 2004.

9. Buchsbaum GM, Chin M, Glantz C and Guzick D: Prevalence of urinary incontinence and associated risk factors in a cohort of nuns. Obstet Gynecol 100: 226-229, 2002.

10. Buchsbaum GM, Duecy EE, Kerr LA, Huang LS and Guzick DS Urinary incontinence in nulliparous women and their parous sisters. Obstet Gynecol 106: 1253-1258, 2005.

11. Bump RC and Norton PA: Epidemiology and natural history of pelvic floor dysfunction. Obstet Gynecol Clin North Am 25 723-746, 1998

12. George G, Joseph J and Ganjifrockwalaa F: Decreased total antioxidant levels and increased oxidative stress in South African type 2 diabetes mellitus patients. J Endocrinol Metab Diabetes South Africa 22: 21-25, 2017.

13. Pham-Huy LA, He H and Pham-Huy C: Free radicals, antioxidants in disease and health. Int J Biomed Sci 4: 89-96, 2008.

14. Turrens JF: Mitochondrial formation of reactive oxygen species. J Physiol 552: 335-344, 2003.

15. Diplock AT: Antioxidants and disease prevention. Mol Aspects Med 15: 293-376, 1994

16. Tsai-Turton $\mathrm{M}$ and Luderer $\mathrm{U}$ : Opposing effects of glutathione depletion and follicle-stimulating hormone on reactive oxygen species and apoptosis in cultured preovulatory rat follicles. Endocrinology 147: 1224-1236, 2006.

17. Choy KW, Liu YM, Chu CY, Wang CC, Lui WT, Lee LL, Pang MW, Rogers MS and Yip SK: High isoprostane level in cardinal ligament-derived fibroblasts and urine sample of women with uterine prolapse. BJOG 115: 1179-1183, 2008.

18. Brigelius-Flohé R and Maiorino M: Glutathione peroxidases. Biochim Biophys Acta 1830: 3289-3303, 2013.
19. Akhtar MS, Lodhi LA, Ahmad I, Qureshi ZI and Muhammad G: Serum trace mineral variations in Nili-Ravi buffaloes suffering with prepartum vaginal prolapse in two different agro-ecological zones of Punjab, Pakistan. Theriogenology 77: 1328-1333, 2012.

20. Kim JY, Kim EJ, Jeon MJ, Kim H, Moon YJ and Bai SW: Association between the poly(ADP-ribose) polymerase-1 gene polymorphism and advanced pelvic organ prolapse. Menopause 21: 177-181, 2014.

21. Visco AG and Yuan L: Differential gene expression in pubococcygeus muscle from patients with pelvic organ prolapse. Am J Obstet Gynecol 189: 102-112, 2003.

22. Akhtar K, Broekelmann TJ, Miao M, Keeley FW, Starcher BC, Pierce RA, Mecham RP and Adair-Kirk TL: Oxidative and nitrosative modifications of tropoelastin prevent elastic fiber assembly in vitro. J Biol Chem 285: 37396-37404, 2010.

23. Fisher GJ, Wang ZQ, Datta SC, Varani J, Kang S and Voorhees JJ: Pathophysiology of premature skin aging induced by ultraviolet light. N Engl J Med 337: 1419-1429, 1997.

24. Fisher GJ, Datta S, Wang Z, Li XY, Quan T, Chung JH, Kang S and Voorhees JJ: c-Jun-dependent inhibition of cutaneous procollagen transcription following ultraviolet irradiation is reversed by all-trans retinoic acid. J Clin Invest 106: 663-670, 2000.

25. Siwik DA, Pagano PJ and Colucci WS: Oxidative stress regulates collagen synthesis and matrix metalloproteinase activity in cardiac fibroblasts. Am J Physiol Cell Physiol 280: C53-C60, 2001.

26. Lang J, Zhu L, Sun Z and Chen J: Clinical study on collagen and stress urinary incontinence. Clin Exp Obstet Gynecol 29: 180-182, 2002.

27. Liapis A, Bakas P, Pafiti A, Frangos-Plemenos M, Arnoyannaki N and Creatsas G: Changes of collagen type III in female patients with genuine stress incontinence and pelvic floor prolapse. Eur J Obstet Gynecol Reprod Biol 97: 76-79, 2001.

28. Ewies AA, Al-Azzawi F and Thompson J: Changes in extracellular matrix proteins in the cardinal ligaments of post-menopausal women with or without prolapse: A computerized immunohistomorphometric analysis. Hum Reprod 18: 2189-2195, 2003.

29. Goepel C,Johanna Kantelhardt E, Karbe I, Stoerer S and Dittmer J: Changes of glycoprotein and collagen immunolocalization in the uterine artery wall of postmenopausal women with and without pelvic organ prolapse. Acta Histochem 113: 375-381, 2011.

30. Söderberg MW, Falconer C, Byström B, Malmström A and Ekman G: Young women with genital prolapse have a low collagen concentration. Acta Obstet Gynecol Scand 83: 1193-1198, 2004.

31. Cooke MS, Evans MD, Dizdaroglu M and Lunec J: Oxidative DNA damage: Mechanisms, mutation, and disease. FASEB J 17: 1195-1214, 2003

32. Lupachyk S, Shevalye H, Maksimchyk Y, Drel VR and Obrosova IG: PARP inhibition alleviates diabetes-induced systemic oxidative stress and neural tissue 4-hydroxynonenal adduct accumulation: Correlation with peripheral nerve function. Free Radic Biol Med 50: 1400-1409, 2011.

33. Yoritaka A, Hattori N, Uchida K, Tanaka M, Stadtman ER and Mizuno Y: Immunohistochemical detection of 4-hydroxynonenal protein adducts in Parkinson disease. Proc Natl Acad Sci USA 93: 2696-2701, 1996.

34. Halliwell B: Why and how should we measure oxidative DNA damage in nutritional studies? How far have we come? Am J Clin Nutr 72: 1082-1087, 2000.

35. Kasai $\mathrm{H}$ : Analysis of a form of oxidative DNA damage, 8-hydroxy-2'-deoxyguanosine, as a marker of cellular oxidative stress during carcinogenesis. Mutat Res 387: 147-163, 1997.

36. Alary J, Guéraud F and Cravedi JP: Fate of 4-hydroxynonenal in vivo: Disposition and metabolic pathways. Mol Aspects Med 24: 177-187, 2003.

37. Dwivedi S, Sharma A, Patrick B, Sharma R and Awasthi YC: Role of 4-hydroxynonenal and its metabolites in signaling. Redox Rep 12: 4-10, 2007.

38. Oberley TD and Oberley LW: Antioxidant enzyme levels in cancer. Histol Histopathol 12: 525-535, 1997.

39. Wallace DC: Mitochondrial diseases in man and mouse. Science 283: 1482-1488, 1999.

40. Arthur JR: The glutathione peroxidases. Cell Mol Life Sci 57: 1825-1835, 2000.

41. DeLancey JO: Anatomie aspects of vaginal eversion after hysterectomy. Am J Obstet Gynecol 166: 1717-1728, 1992.

42. Martin CM and O'Leary JJ: Histology of cervical intraepithelial neoplasia and the role of biomarkers. Best Pract Res Clin Obstet Gynaecol 25: 605-615, 2011. 
43. Bump RC, Mattiasson A, Bø K, Brubaker LP, DeLancey JO, Klarskov P, Shull BL and Smith AR: The standardization of terminology of female pelvic organ prolapse and pelvic floor dysfunction. Am J Obstet Gynecol 175: 10-17, 1996.

44. Santulli P, Borghese B, Lemaréchal H,Leconte M, Millischer AE, Batteux F, Chapron C and Borderie D: Increased serum oxidative stress markers in women with uterine leiomyoma. PLoS One 8: e72069, 2013

45. Scutiero G, Iannone P, Bernardi G, Bonaccorsi G, Spadaro S, Volta CA, Greco P and Nappi L: Oxidative stress and endometriosis: A systematic review of the literature. Oxid Med Cell Longev 2017: 7265238, 2017.

46. Lugogo NL, Bappanad D and Kraft M: Obesity, metabolic dysregulation and oxidative stress in asthma. Biochim Biophys Acta 1810: 1120-1126, 2011.

47. Dikalov SI and Ungvari Z: Role of mitochondrial oxidative stress in hypertension. Am J Physiol Heart Circ Physiol 305 H1417-H1427, 2013.

48. Livak KJ and Schmittgen TD: Analysis of relative gene expression data using real-time quantitative PCR and the 2(-Delta Delta C(T)) method. Methods 25: 402-408, 2001.

49. Takacs P, Gualtieri M, Nassiri M, Candiotti K and Medina CA: Vaginal smooth muscle cell apoptosis is increased in women with pelvic organ prolapse. Int Urogynecol J Pelvic Floor Dysfunct 19: 1559-1564, 2008.

50. Takacs P, Nassiri M, Gualtieri M, Candiotti K and Medina CA Uterosacral ligament smooth muscle cell apoptosis is increased in women with uterine prolapse. Reprod Sci 16: 447-452, 2009.

51. Kim EJ, Chung N, Park SH, Lee KH, Kim SW, Kim JY, Bai SW and Jeon MJ: Involvement of oxidative stress and mitochondrial apoptosis in the pathogenesis of pelvic organ prolapse. J Urol 189 588-594, 2013.

52. Li S, Tan HY, Wang N, Zhang ZJ, Lao L, Wong CW and Feng Y: The role of oxidative stress and antioxidants in liver diseases. Int J Mol Sci 16: 26087-26124, 2015

53. Perl A: Oxidative stress in the pathology and treatment of systemic lupus erythematosus. Nat Rev Rheumatol 9: 674-686, 2013.

54. Lindblom R, Higgins G, Coughlan M and de Haan JB: Targeting mitochondria and reactive oxygen Species-driven pathogenesis in diabetic nephropathy. Rev Diabet Stud 12: 134-156, 2015.

55. Nita M and Grzybowski A: The role of the reactive oxygen species and oxidative stress in the pathomechanism of the Age-related ocular diseases and other pathologies of the anterior and posterior eye segments in adults. Oxid Med Cell Longev 2016 3164734, 2016.

56. Styskal J, Van Remmen H, Richardson A and Salmon AB: Oxidative stress and diabetes: What can we learn about insulin resistance from antioxidant mutant mouse models? Free Radic Biol Med 52: 46-58, 2012.

57. Baas AS and Berk BC: Differential activation of mitogen-activated protein kinases by $\mathrm{H} 2 \mathrm{O} 2$ and $\mathrm{O} 2$ - in vascular smooth muscle cells. Circ Res 77: 29-36, 1995.

58. Ushio-Fukai M, Alexander RW, Akers M and Griendling KK p38 Mitogen-activated protein kinase is a critical component of the redox-sensitive signaling pathways activated by angiotensin II. Role in vascular smooth muscle cell hypertrophy. J Biol Chem 273: 15022-15029, 1998.

59. Ushio-Fukai M, Alexander RW, Akers M, Yin Q, Fujio Y, Walsh K and Griendling KK: Reactive oxygen species mediate the activation of $\mathrm{Akt} /$ protein kinase $\mathrm{B}$ by angiotensin II in vascular smooth muscle cells. J Biol Chem 274: 22699-22704, 1999.

60. Sundaresan M, Yu ZX, Ferrans VJ, Irani K and Finkel T: Requirement for generation of $\mathrm{H} 2 \mathrm{O} 2$ for platelet-derived growth factor signal transduction. Science 270: 296-299, 1995.

61. Zafari AM, Ushio-Fukai M, Akers M, Yin Q, Shah A, Harrison DG, Taylor WR and Griendling KK: Role of $\mathrm{NADH} / \mathrm{NADPH}$ oxidase-derived $\mathrm{H} 2 \mathrm{O} 2$ in angiotensin II-induced vascular hypertrophy. Hypertension 32: 488-495, 1998.

62. Ushio-Fukai M, Zafari AM, Fukui T, Ishizaka $\mathrm{N}$ and Griendling KK: p22phox is a critical component of the superoxide-generating NADH/NADPH oxidase system and regulates angiotensin II-induced hypertrophy in vascular smooth muscle cells. J Biol Chem 271: 23317-23321, 1996.

63. Ballinger SW, Patterson C, Yan CN, Doan R, Burow DL, Young CG, Yakes FM, Van Houten B, Ballinger CA, Freeman BA and Runge MS: Hydrogen peroxide- and peroxynitrite-induced mitochondrial DNA damage and dysfunction in vascular endothelial and smooth muscle cells. Circ Res 86: 960-966, 2000.
64. Kiningham KK, Oberley TD, Lin S, Mattingly CA and St Clair DK: Overexpression of manganese superoxide dismutase protects against mitochondrial-initiated poly(ADP-ribose) polymerase-mediated cell death. FASEB J 13: 1601-1610, 1999.

65. Lin MT and Beal MF: Mitochondrial dysfunction and oxidative stress in neurodegenerative diseases. Nature 443: 787-795, 2006.

66. Čáp M, Váchová L and Palková Z: Reactive oxygen species in the signaling and adaptation of multicellular microbial communities. Oxid Med Cell Longev 2012: 976753, 2012.

67. Scherz-Shouval R and Elazar Z: Regulation of autophagy by ROS: Physiology and pathology. Trends Biochem Sci 36: 30-38, 2011.

68. Vernon PJ and Tang D: Eat-me: Autophagy, phagocytosis, and reactive oxygen species signaling. Antioxid Redox Signal 18: 677-691, 2013

69. Owens MW, Milligan SA, Jourd'heuil D and Grisham MB: Effects of reactive metabolites of oxygen and nitrogen on gelatinase A activity. Am J Physiol 273: L445-L450, 1997.

70. Viappiani S, Nicolescu AC, Holt A, Sawicki G, Crawford BD, León H, van Mulligen T and Schulz R: Activation and modulation of $72 \mathrm{kDa}$ matrix metalloproteinase-2 by peroxynitrite and glutathione. Biochem Pharmacol 77: 826-834, 2009.

71. Kim NN, Villegas S, Summerour SR and Villarreal FJ: Regulation of cardiac fibroblast extracellular matrix production by bradykinin and nitric oxide. J Mol Cell Cardiol 31: 457-466, 1999.

72. Liang CC, Huang HY and Chang SD: Gene expression and immunoreactivity of elastolytic enzymes in the uterosacral ligaments from women with uterine prolapse. Reprod Sci 19: 354-359, 2012

73. Donnini S, Monti M, Roncone R, Morbidelli L, Rocchigiani M, Oliviero S, Casella L, Giachetti A, Schulz R and Ziche M: Peroxynitrite inactivates human-tissue inhibitor of metalloproteinase-4. FEBS Lett 582: 1135-1140, 2008

74. Mayne ST: Antioxidant nutrients and chronic disease: Use of biomarkers of exposure and oxidative stress status in epidemiologic research. J Nutr 133 (Suppl 3): 933S-940S, 2003.

75. Kulms D, Zeise E, Poeppelmann B and Schwarz T: DNA damage, death receptor activation and reactive oxygen species contribute to ultraviolet radiation-induced apoptosis in an essential and independent way. Oncogene 21: 5844-5851, 2002.

76. Kaneko T, Tahara S and Matsuo M: Non-linear accumulation of 8-hydroxy-2'-deoxyguanosine, a marker of oxidized DNA damage, during aging. Mutat Res 316: 277-285, 1996.

77. Awasthi YC, Sharma R, Sharma A, Yadav S, Singhal SS, Chaudhary $P$ and Awasthi S: Self-regulatory role of 4-hydroxynonenal in signaling for stress-induced programmed cell death. Free Radic Biol Med 45: 111-118, 2008

78. Cheng JZ, Singhal SS, Saini M, Singhal J, Piper JT, Van Kuijk F, Zimniak P, Awasthi YC and Awasthi S: Effects of mGST A4 transfection on 4-hydroxynonenal-mediated apoptosis and differentiation of K562 human erythroleukemia cells. Arch Biochem Biophys 372: 29-36, 1999.

79. Li J, Sharma R, Patrick B, Sharma A, Jeyabal PV, Reddy PM, Saini MK, Dwivedi S, Dhanani S, Ansari NH, et al: Regulation of CD95 (Fas) expression and Fas-mediated apoptotic signaling in HLE B-3 cells by 4-hydroxynonenal. Biochemistry 45: 12253-12264, 2006.

80. Sharma R, Brown D, Awasthi S, Yang Y, Sharma A, Patrick B, Saini MK, Singh SP, Zimniak P, Singh SV and Awasthi YC: Transfection with 4-hydroxynonenal-metabolizing glutathione S-transferase isozymes leads to phenotypic transformation and immortalization of adherent cells. Eur J Biochem 271: 1690-1701, 2004

81. Sharma R, Sharma A, Dwivedi S, Zimniak P, Awasthi S and Awasthi YC: 4-Hydroxynonenal self-limits fas-mediated DISC-independent apoptosis by promoting export of Daxx from the nucleus to the cytosol and its binding to Fas. Biochemistry 47: 143-156, 2008

82. Chaudhary P, Sharma R, Sharma A, Vatsyayan R, Yadav S, Singhal SS, Rauniyar N, Prokai L, Awasthi S and Awasthi YC: Mechanisms of 4-hydroxy-2-nonenal induced pro-and anti-apoptotic signaling. Biochemistry 49: 6263-6275, 2010.

83. Forgione MA, Weiss N, Heydrick S, Cap A, Klings ES, Bierl C Eberhardt RT, Farber HW and Loscalzo J: Cellular glutathione peroxidase deficiency and endothelial dysfunction. Am J Physiol Heart Circ Physiol 282: H1255-H1261, 2002.

84. Thu VT, Kim HK, Ha SH, Yoo JY, Park WS, Kim N, Oh GT and Han J: Glutathione peroxidase 1 protects mitochondria against hypoxia/reoxygenation damage in mouse hearts. Pflugers Arch 460: 55-68, 2010 . 
85. Jang YC, Pérez VI, Song W, Lustgarten MS, Salmon AB, Mele J, Qi W, Liu Y, Liang H, Chaudhuri A, et al: Overexpression of Mn superoxide dismutase does not increase life span in mice. J Gerontol A Biol Sci Med Sci 64: 1114-1125, 2009.

86. Zhang Y,Zhang HM, Shi Y, Lustgarten M, Li Y, Qi W, Zhang BX and Van Remmen H: Loss of manganese superoxide dismutase leads to abnormal growth and signal transduction in mouse embryonic fibroblasts. Free Radic Biol Med 49: 1255-1262, 2010.

87. Kwak HB, Lee Y, Kim JH, Van Remmen H, Richardson AG and Lawler JM: MnSOD overexpression reduces fibrosis and Pro-apoptotic signaling in the aging mouse heart. J Gerontol A Biol Sci Med Sci 70: 533-544, 2015.

88. Eldridge A, Fan M, Woloschak G, Grdina DJ, Chromy BA and Li J: Manganese superoxide dismutase interacts with a large scale of cellular and mitochondrial proteins in low-dose radiation-induced adaptive radioprotection. Free Radic Biol Med 53: 1838-1847, 2012.

89. Smolik AC, Bengez-Pudja L, Cheng I and Mascotti DP: Characterization of E. coli manganese superoxide dismutase binding to RNA and DNA. Biochim Biophys Acta 1844: 2251-2256, 2014.

90. Holley AK, Dhar SK, Xu Y and St Clair DK: Manganese superoxide dismutase: Beyond life and death. Amino Acids 42: 139-158, 2012

91. Silva JP, Shabalina IG, Dufour E, Petrovic N, Backlund EC, Hultenby K, Wibom R, Nedergaard J, Cannon B and Larsson NG: SOD2 overexpression: Enhanced mitochondrial tolerance but absence of effect on UCP activity. EMBO J 24 4061-4070, 2005.

92. Motoori S, Majima HJ, Ebara M, Kato H, Hirai F, Kakinuma S, Yamaguchi C, Ozawa T, Nagano T, Tsujii $\mathrm{H}$ and Saisho H: Overexpression of mitochondrial manganese superoxide dismutase protects against radiation-induced cell death in the human hepatocellular carcinoma cell line HLE. Cancer Res 61 5382-5388, 2001.

93. Suzuki K, Murtuza B, Sammut IA, Latif N, Jayakumar J, Smolenski RT, Kaneda Y, Sawa Y, Matsuda H and Yacoub MH: Heat shock protein 72 enhances manganese superoxide dismutase activity during myocardial ischemia-reperfusion injury, associated with mitochondrial protection and apoptosis reduction. Circulation 106 (12 Suppl 1): I270-I276, 2002.
94. Boreham MK, Wai CY, Miller RT, Schaffer JI and Word RA Morphometric properties of the posterior vaginal wall in women with pelvic organ prolapse. Am J Obstet Gynecol 187 1501-1509, 2002.

95. Boreham MK, Wai CY, Miller RT, Schaffer JI and Word R Morphometric analysis of smooth muscle in the anterior vaginal wall of women with pelvic organ prolapse. Am J Obstet Gynecol 187: 56-63, 2002.

96. Gabriel B, Denschlag D, Göbel H, Fittkow C, Werner M, Gitsch $G$ and Watermann D: Uterosacral ligament in postmenopausal women with or without pelvic organ prolapse. Int Urogynecol J Pelvic Floor Dysfunct 16: 475-479, 2005.

97. Ozdegirmenci O, Karslioglu Y, Dede S, Karadeniz S, Haberal A, Gunhan O and Celasun B: Smooth muscle fraction of the round ligament in women with pelvic organ prolapse: A computer-based morphometric analysis. Int Urogynecol J Pelvic Floor Dysfunct 16: 39-43, 2005.

98. Bermingham EN, Hesketh JE, Sinclair BR, Koolaard JP and Roy NC: Selenium-enriched foods are more effective at increasing glutathione peroxidase (GPx) activity compared with selenomethionine: A meta-analysis. Nutrients 6: 4002-4031, 2014.

99. Kwak HB, Song W and Lawler JM: Exercise training attenuates age-induced elevation in $\mathrm{Bax} / \mathrm{Bcl}-2$ ratio, apoptosis, and remodeling in the rat heart. FASEB J 20: 791-793, 2006.

100. Kwak HB, Kim JH, Joshi K, Yeh A, Martinez DA and Lawler JM: Exercise training reduces fibrosis and matrix metalloproteinase dysregulation in the aging rat heart. FASEB J 25: 1106-1117, 2011

101. Lawler JM, Kwak HB, Kim JH and Suk MH: Exercise training inducibility of MnSOD protein expression and activity is retained while reducing prooxidant signaling in the heart of senescent rats. Am J Physiol Regul Integr Comp Physiol 296: R1496-R1502, 2009.

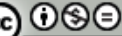

This work is licensed under a Creative Commons Attribution-NonCommercial-NoDerivatives 4.0 International (CC BY-NC-ND 4.0) License. 